\title{
Identification and expression of the WRKY transcription factors of Carica papaya in response to abiotic and biotic stresses
}

\author{
Lin-jie Pan $\cdot$ Ling Jiang
}

Received: 2 August 2012/Accepted: 23 December 2013/Published online: 4 January 2014

(C) The Author(s) 2014. This article is published with open access at Springerlink.com

\begin{abstract}
The WRKY transcription factor (TF) plays a very important role in the response of plants to various abiotic and biotic stresses. A local papaya database was built according to the GenBank expressed sequence tag database using the BioEdit software. Fifty-two coding sequences of Carica papaya WRKY TFs were predicted using the tBLASTn tool. The phylogenetic tree of the WRKY proteins was classified. The expression profiles of 13 selected $C$. papaya WRKY TF genes under stress induction were constructed by quantitative real-time polymerase chain reaction. The expression levels of these WRKY genes in response to 3 abiotic and 2 biotic stresses were evaluated. $\mathrm{TF}_{807.3}$ and $\mathrm{TF}_{72.14}$ are upregulated by low temperature; $\mathrm{TF}_{807.3}, \mathrm{TF}_{43.76}, \mathrm{TF}_{12.199}$ and $\mathrm{TF}_{12.62}$ are involved in the response to drought stress; $\mathrm{TF}_{9.35}, \mathrm{TF}_{18.51}$, $\mathrm{TF}_{72.14}$ and $\mathrm{TF}_{12.199}$ is involved in response to wound; $\mathrm{TF}_{12.199}, \mathrm{TF}_{807.3}, \mathrm{TF}_{21.156}$ and $\mathrm{TF}_{18.51}$ was induced by PRSV pathogen; $\mathrm{TF}_{72.14}$ and $\mathrm{TF}_{43.76}$ are upregulated by $\mathrm{SA}$. The regulated expression levels of above eight genes normalized against housekeeping gene actin were significant at probability of 0.01 levels. These WRKY TFs could be related to corresponding stress resistance and selected as the candidate genes, especially, the two genes $\mathrm{TF}_{807.3}$ and $\mathrm{TF}_{12.199}$, which were regulated notably by four stresses
\end{abstract}

Electronic supplementary material The online version of this article (doi:10.1007/s11033-013-2966-8) contains supplementary material, which is available to authorized users.

L. Pan $\cdot$ L. Jiang $(\square)$

College of the Department of Horticulture and Forestry of Huazhong Agricultural University, Key Laboratory of Horticultural Plant Biology of Ministry of Education, National Indoor Conservation Center of Virus-free Gemplasms of Fruit Crops, Wuhan 430070, Hubei, China

e-mail: jiangling@mail.hzau.edu.cn respectively. This study may provide useful information and candidate genes for the development of transgenic stress tolerant papaya varieties.

Keywords Carica papaya L. · WRKY transcription factor - Quantitative real time PCR (qRT-PCR) - Biotic stress - Abiotic stress · Papaya ringspot virus (PRSV)

$\begin{array}{ll}\text { Abbreviations } \\ \text { AS } & \text { Salicylic acid } \\ \text { TF } & \text { Transcription factor } \\ \text { TFPs } & \text { Transcription factor proteins } \\ \text { ZF } & \text { Zinc finger } \\ \text { CDS } & \text { Coding sequence } \\ \text { WRKY } & \text { Transcriptional regulatory factors in which } \\ & \text { N-terminal ends contain a conserved } \\ & \text { WRKYGQR amino acids sequences } \\ \text { PBS } & \text { Phosphate buffer solution }\end{array}$

\section{Introduction}

Carica papaya is an economically important fruit in southern China as well as other tropic and sub-tropic countries. Its flower bud formation and fruit production are susceptible to abiotic and biotic stresses such as extreme temperatures, seasonal droughts, typhoon wounds, and papaya ringspot virus (PRSV). These stresses may cause severe economic loss in papaya production in China. The development of transgenic Papaya varieties that are more tolerant to these stresses could be an effective approach to the problems.

Plants have multiple mechanisms for adapting to abiotic and biotic stresses in their natural habitats [1, 12]. Research 
on the responses of plants to their environments has been focused on the gene regulation of transcriptional level. Transcription factors (TFs) are proteins that can activate or restrain the transcription of downstream target genes by binding directly to promoters of target genes in a sequencespecific mode [37]. The WRKY TFs form one of the largest families and play a broad-spectrum regulatory role as positive and negative regulators in the responses to abiotic and biotic stresses in plants [1].

Proteins of the WRKY gene family contain one or two highly conserved WRKY domains and a zinc finger motif in the C-terminal region [10]. WRKY proteins containing a single WRKY domain with the C2-H2 (C-X4-5-C-X22-23$\mathrm{H}-\mathrm{X} 1-\mathrm{H})$ pattern are group I, WRKY proteins containing two WRKY domain followed by a $\mathrm{C} 2 \mathrm{H} 2$ are group II; WRKY proteins containing a single WRKY domain with C2-HC (C-X7-C-X23-H-X1-C) pattern are group III; group IV especially for WRKY proteins that contain a WRKY domain but lack a complete zinc finger [10, 41]. The WRKY domain can bind to the TTGAC $(\mathrm{C} / \mathrm{T})$ of W-box found in promoters of target genes and regulates its transcription [44]. WRKY family members appear to be involved in the regulation of various physiological and development processes in plants, such as senescence, embryogenesis, regulation of biosynthetic pathways, hormone signaling, etc. [42].

$W R K Y$ genes are frequently reported to be involved in various stress responses. The WRKY proteins have been observed in response to various pathogenic infections, such as fungal, bacterial, and viral $[11,17,29,39]$. Some WRKYS are induced by pathogen infection, and activated by other elicitors such as SA or wounding [2]. Hwang et al. [15] reported the heterologous expression of OsWRKY6 gene in Arabidopsis activates the expression of defense related genes and enhances resistance to pathogens. WRKY TFs have also been shown to regulate cross-talk between jasmonate- and salicylate-regulated disease response pathways [56]. Different stresses have been reported to induce the expression of various $W R K Y$ TFs. For example, SA induces AtWRKY3, BnWRKY, CaWRKYl, FaWRKYl, $H v W R K Y 38$, and $O s W R K Y$ [8, 23, 36, 40, 43, 48, 50]; cold stress induces $H v W R K Y$ and $L t W R K Y$ [32, 59, 60]; drought induces $H v W R K Y$ and $O s W R K Y$ [40, 43]; and wound induces LtWRKY, OsWRKY, OsWRKY, PtWRKY, VvWRKY, and $W t W R K Y[24,31]$. Many WRKY TFs are activators, such as AtWRKY3 and AtWRKY4 [23], CaWRKYb [17]. Some WRKYs, however, are repressors, such as AtWRKY62 [22], OsWRKY51 and OsWRKY71 [47].

The rapid and effective quantitative real-time polymerase chain reaction (qPCR) is still considered to be the effective method for the comprehensive quantification analysis of WRKY expression at the genome level [21, 52]. Since the identification of the first WRKY protein, SPF1, from sweet potato (Ipomoea batatas) [16], large numbers of WRKY genes have been cloned from various plant species including potato [6], tobacco [53], wheat and barley [44], Arabidopsis [3, 4, 15, 49, 56], pepper [38, 57], grape [31], rice [40, 41, 55], capsicum [36], populus [24], canola [50], Cucumis sativus [27], cotton [52], etc. Although numerous WRKY genes have been identified or predicted from many different species, only a small number of them have been functionally characterized in Arabidopsis, soybean, rice, tobacco, etc. [26]. The WRKY genes of papaya have been confirmed since the whole genome sequence of the papaya plant has been completed [33].

Dong et al. [7] reported the expression profile of WRKY against pathogenic stress in Arabidopsis, and induced expression was detected in 49 out of the 72 tested WRKY genes. Ming et al. [33] reported 52 WRKYs in papaya. However, the number of WRKYs in papaya responsible to stresses remains unknown. And the WRKY genes have not yet been functionally characterized.

The purpose of present study is to build a local database for $W R K Y$ genes in papaya, to construct a phylogenetic tree using the domain amino acid sequences of these WRKY proteins, and to detect the expression profiles of selected candidate WRKYs under various stressed conditions and predict the possible functions based on their expression patterns. This research may provide useful information and candidate genes for the development of transgenic stress tolerant papaya varieties.

\section{Materials and methods}

\section{Materials and treatments}

Seedlings of C. papaya L. 'Sunup' provided by the Institute of Agriculture Science in Fujian Province were cultured at $28{ }^{\circ} \mathrm{C}$,under a photoperiod of $14 \mathrm{~h} /$ day. Stress treatments were performed on 30-day-old seedlings with four to five leaves. $1 \mathrm{mmol} / \mathrm{L} \mathrm{SA}$ was sprayed onto the cotyledons and two euphilla at a dose of $10 \mathrm{ml} / \mathrm{plant}$. Afterwards, the leaves were collected $12 \mathrm{~h}$ after treatment. Plants treated with only water served as the control. The stress and control groups were kept in different growth chambers. Rubbing quartz sands on the surface of leaves, producing small cuts, performed wound treatment. Keeping the plants at $4{ }^{\circ} \mathrm{C}$ for $12 \mathrm{~h}$ imposed a low temperature stress, whereas the control plants were grown at $28{ }^{\circ} \mathrm{C}$, at dark. Drought stress was induced by not providing water for 1 week with the quadrate plastic pot of $12 \mathrm{~cm}$ in height, and $10 \mathrm{~cm}$ in width, whereas the control group was regularly watered. PRSV pathogens were identified by reverse transcriptase (RT)-PCR. The leaves (provided by the Fruit Institute of Guangdong Province) were inoculated with 
pathogen juice in phosphate-buffered saline (PBS), whereas the control plant was inoculated only with PBS, the samples were collected after $24 \mathrm{~h}$. The leaves were harvested at certain time points as indicated in each experiment, frozen with liquid nitrogen, and stored at $-80{ }^{\circ} \mathrm{C}$ until RNA extraction. The basal levels of WRKY expression were evaluated and normalized to the actin transcript level of papaya. Each treatment involved the leaves of five plants, and samples were taken from experiments conducted in triplicate.

\section{Database collection and gene annotation}

The protein sequence corresponding to each papaya WRKY unigene was determined by SUPERFAMILY (http://supfam. org/SUPERFAMILY/index.html). Utilizing GenBank information, the BLAST local database of the expressed sequence tags (ESTs) of papaya was constructed using the BioEdit software with EST sequences (EX227656-EX303501) for comparison and confirmation of the nucleotide sequence of the WRKY genes. The operator procedure is following: download the genomics coding sequence of "Sunup" of papaya from NCBI database, and save the genomics sequences with FASTA file format, a local nucleotide database file was created, it was named "papaya.aa". To startup BioEdit software program, selected Accessory Application and use BLAST function, and then, paste the amino acid sequence, and selecting blast function and the nucleotide sequence of WRKY ZF were confirmed in papaya. The specific WRKYtype domain signature and WRKYGQK heptapeptide motif were compared using the BioEdit software. The specific ZF WRKY-type domain signatures were also investigated by searching the ExPasy proteomics server (http://cn.expasy. org). The WRKY amino acid sequences were aligned, and a phylogenetic tree was constructed using DNAman software.

\section{RNA extraction and qRT-PCR analysis}

Total RNA was extracted using TRIzol reagent (Invitrogen) following the manufacturer's instruction, with DNase I digestion for purification. The RNA samples were detected using an Ultrospec 2100 UV/Visible spectrophotometer (Amershan GE Healthcare, USA). First-strand cDNA was synthesized from $2 \mu \mathrm{g}$ of total RNA in a $20-\mu \mathrm{L}$ final volume using an M-MLV first-strand cDNA kit. qPCR was performed using Platinum SYBR Green qPCR Super Mix-UDG (Invitrogen) following the manufacturer's instruction. A real-time qPCR assay for gene expressionspecific primers was designed from the papaya cDNA sequences using the Primer Express 5.0 software at $58-60{ }^{\circ} \mathrm{C}$. The amplification fragment lengths were 98-193 bp. The primer sequences are shown in
Supplemental Table 2. These primers were designed with Primer 5-cracked software, the primers were synthesized by Sanggon Shanghai Biology Technology, Ltd. qRT-PCR was performed using Rator 6000 (Corbett). The primers were strictly filtrated by reverse transcription test and amplified the single band.

The cycling conditions started with 2 min of polymerase activity at $95{ }^{\circ} \mathrm{C}$ and 40 cycles at $95{ }^{\circ} \mathrm{C}$ for $20 \mathrm{~s}$, followed by $60{ }^{\circ} \mathrm{C}$ for $20 \mathrm{~s}$ and $72{ }^{\circ} \mathrm{C}$ for $20 \mathrm{~s}$. Each assay was conducted in triplicate, and a no-template control was included. The threshold cycle $(\mathrm{Ct})$ of the primary amplification curve was used for calculations. The actin gene was chosen as the internal constitutively expressed control (normalization) according to the formula $\Delta \Delta \mathrm{Ct}=\left(\mathrm{C}_{\mathrm{t}, \text { target }}-\mathrm{C}_{\mathrm{t}, \text { Actin }}\right)$ time $x$ $-\left(\mathrm{C}_{\mathrm{t} \text {, target }}-\mathrm{C}_{\mathrm{t}, \text { Actin }}\right)$ time 0. The relative expression level was analyzed using the $2^{-\Delta \Delta \mathrm{Ct}}$ method [30]. Dilutions of cDNA (1:10 to $1: 1,000)$ from a reference sample were used to construct a relative standard curve. The specificity of the PCR products was verified by melting curve analyses $\left(60-95{ }^{\circ} \mathrm{C}\right)$. Only primer sets producing a single sequence-specific peak in the dissociator curve were conserved. The data were analyzed using the Roter Gene 6000 Series software (VIRTUAL Mode software package) to obtain the relative expression levels of the papaya gene based on the comparative $\mathrm{Ct}$ method. The significant differences among the data were analyzed via $t$ tests using Microsoft Excel. Data are represented as means and standard errors of three replicates.

\section{Results}

Identification of WRKY TFs and their nucleic acid sequence in papaya

A total of 52 significant WRKY domains in 50 proteins have been predicted using the SUPERFAMILY database of C. Papaya. In the present study, after analyzing the homology of the putative amino acid sequence and eliminating redundancies, 52 nucleic acid coding sequences of C. Papaya WRKY TFs were identified using the tBLASTn tool. These data were mined from 47483 papaya ESTs in the C. Papaya genome. The numbers of TFs, relative GenBank accession numbers, protein size, amino acid positions, frame and available nucleic acid sequence, WRKY type domain signature are shown in Supplement Table 1.

To examine the evolutionary relationships among the WRKY domains, a phylogenetic tree was constructed using the conserved WRKY domain amino acid sequences. The phylogenetic tree demonstrated that the 52 WRKYs could be classified into 4 groups according to the most prominent feature of these proteins, the WRKY domain, which contained 60 amino acids. Group I includes 6 


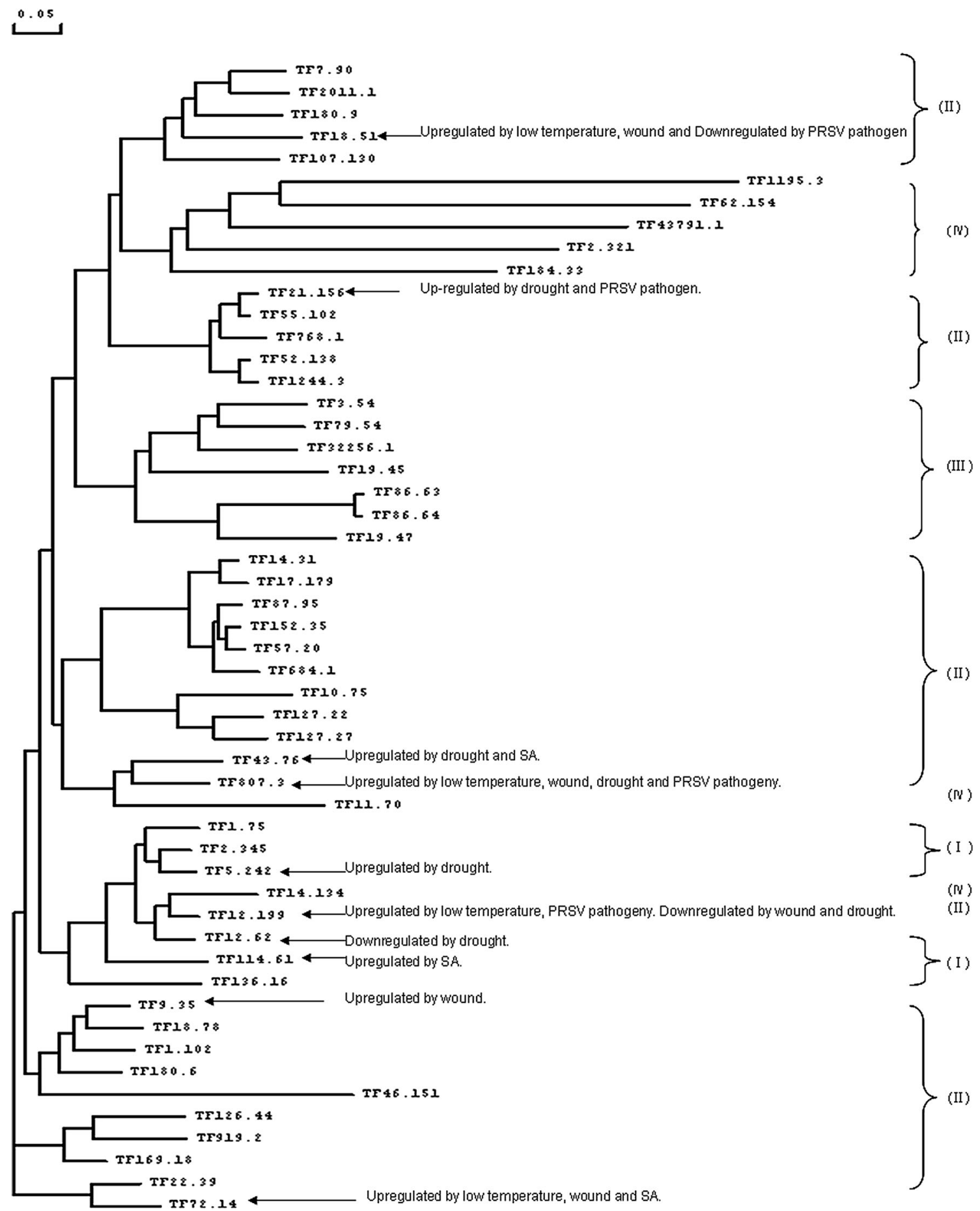

Fig. 1 Phylogenetic unrooted tree of the WRKYs in C. papaya. Relationships among WRKY TF, as illustrates by phyogenetic tree produced by DNAMAN. WRKYs were classified into groups I, II, III and IV

WRKYs that have two standard WRKYGQK heptapeptide followed by a $\mathrm{C} 2 \mathrm{H} 2$. Group II includes 32 WRKYs that have a conserved WRKYGQK heptapeptide followed by a zine finger $\mathrm{CX}_{4-5} \mathrm{CX}_{22-23} \mathrm{HHX}_{1} \mathrm{H}$. Group III includes 7
WRKYs that have a conserved WRKYGQK heptapeptide followed by a C2HC. And group IV includes 5 WRKYs that do not contain the standard WRKYGQK domain and 2 WRKYs that do not contain the zine finger 
WRKY type domain Zinc finger of $\mathrm{CX}_{4-5} \mathrm{CX}_{22-23} \mathrm{HX}_{4} \mathrm{H}$

TF?.90

TF2011.1

TF3.54

TF79.54

TF 32256.1

TF86. 63

TF86. 64

TF19.47

TF14.31

TF17. 179

TF87. 95

TF152.35

TF57.20

TF684.1

TF10. 75

TF127.22

TF1.75

TF14. 134

TF12.199

TF12.62

TF136.16

TF2.345

TF5.242

TF114. 61

TE 43.76

TF807.3

TF11. 70

TF9.35

TF18.78

TF126. 44

TF919.2

TF1.102

TF22.39

TF72.14

TF180. 6

TF21. 156

TF55.102

TF768.1

TF52.138

TF1244.3

TF18.51

TF127.27

TF169.18

TF1195.3

TF107.130

TF180. 9

TF184.33

TF2.321

TF19.45

TF46.151

TF 43791.1

TF62. 154

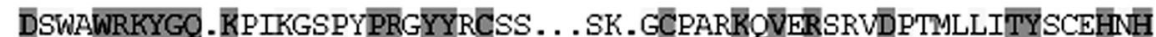
DLWAWRKYGQ. KPIKGSPYPRGYYRCSS ... SK. GCSARKQVERSRTDPNMLVITYTSEHNH DGFSWRKYGQ. KDILGAKYPRGYYRCTHRN , VQ . GCLATKQVCRSDEDTTIFEITYRGRHTC DGYSWRKYGQ. KDILGAKYPRSYYRCTYRN. TQ. NCWATKQVCRSDKDPTIEEVTYRGVHAC DGYCWRKYGQ . KDILGSNFPRGYYRCTHRH . TE . GCLATKQVCRSDSDPTVEEVTYRGRHTC DGFAWRKYGQ. KDILKANHPRSYERCTHKT. DQ . KCQATKQVCKIRDDPPLYRTTYYGHHTC DGFAWRKYGQ. KDILKAINHPRSYERCTHKN . DQ . KCQATKQVCKIRDDPPLYRTTYYGHHTC DGHAWRKYGQ. KDILNAKFPRSYERCTHKY . DQ . GCKATKQVCRLEHDPQCYOTTYIGDHTC DGCOWRKYGQ . KIAKGNPCPRAYYRCTV . . . AP . GCPVRKQVCRCAEDMSILITTYEGTHNH DGCQWRKYGQ. KVAKGNPCPRAYYRCTV . . . AP . SCPVRKQVCRCADDMSILITTYEGTHNH DGCOWRKYGQ. KMAKGNPCPRAYYRCTM . . . AA . GCPVRKQVCRCAEDRTILITTYEGNHNH DGCOWRKYGQ . KMAKGNPCPRAYYRCTM . . . AV . GCPVRKQVCRCAEDRSILITTYEGNHNH DGCQWRKYGQ. KMAKGNPCPRAYYRCTM . . . AV . GCPVRKQVCRCADDKSILITTYEGNHNH DGCQWRKYGQ. KMAKGNPCPRAYYRCTM. . . AT . SCPVRKQVCRCAEDKTILVTTYEGNHNH DGYLWRKYGQ . KVTRDNPSPRAYYKCAL . . . AP . SCPVKKKVCRSIEDQSVIVATYEGEHTH DGYQWRKYGQ . KVTRDNPSPRAYFKCSF . . AP . GCPVKKKVCRSAEDPSILIATYEGEHNH DGYKWRKYGQ . KVWKGNPYPRSYYKCTTF . . . . GCNVRKHVERASTDARAVITTYEGKHNH YIYR ........... SYYKCTSA. . . . GCSVRKHVERASTDPKAVITTYEGKHNH DGYRWRKYGQ.KVVRGNPNPRSYYKCTNA. . . . GCPVRKHVERASHDPKAVITTYEGKHNH DGYRWRKYGQ . KVWKGNPNPRSYYKCTSA. . . . . GCTVRKHVERASHDLKSVITTYEGKHNH DGYRWRKYGQ. KLVKGNPHPRSYYRCSSP . . . . GCRVKKLVERTSHDPKLLTTTYEGHHDH DGYRWRKYGQ . KVVKGNPNPRSYYKCTYP. . . . GCPVRKHVERASHDLRAVITTYEGKHNH DGYRWRKYGQ. KVVKGNPNPRSYYKCTTV. . . . . GCPVRKHVERASQDVRAVITTYEGKHNH DGFRWRKYGQ . KHVKGNPYPRSYYRCTSI . . . . KCNVRKIHVERASDDPVAEITTYEGKHNH DGYRWRKYGQ. KPVKNNKYPRSYYRCTHK . . . . GCNVKKQICRLTKDEGTVTTYEGIHSH DGYRWRKYGQ.KTVKNNKFPRSYYKCTYK. . . . GCNVKKQVCRSSIDEQIVVTTYEGIHTH DKRKGGS. SRMKKATRPRSYYRCTHH. . . . . TCNVKKQVCRLSKDTSTVVTTYEGIHNH DGYRWRKYGQ. KAVKNSPYPRSYYRCTSG. . . . . GOGVKKRVERSSEDPTTVVTYEGOHTH DGYRWRKYGQ. KAVKNSPFPRSYYRCTSA. . . . SCNVKKRVERSCSDPTTVITYEGOHTH DGFKWRKYGK. KMVKNSPNPRNYYKCSIE . . . . GCPVKKRVERDKEDPSYIITTYEGEHNH DGFKWRKYGK. KSVKNSPNPRNYYKCSSR . . . . . GCHVKKRIERERDDPR YVITTYEGTHNH DGYRWRKYGQ. KAVKNSPFPRSYYRCTNS. . . . KCSVKKRVERSSEDPT TVITTYEGOHCH DGYKWRKYGQ KVWKNSLHPRSYYRCTHN. . . . . NCRVKKRVERLSEDCRMVITTYEGRHNH DGYKWRKYGQ . KVWKNTQHPRSYYRCTQL . . . . . NCRVKKRVERLAEDPRMVITTYEGRHVH DGYRWRKYGQ.KFVKNSVQPR

DDYSWRKYGQ. KPIKGSPHPRGYYKCSSV . . . RGCPARKLVERALDDPMMLIVTYEGDHNH DDYSWRKYGQ . KPIKGSPHPRGYYKCSSV . . . . RGCPARKHVERALDDPSMLIVTYEGEHNH DEYSWRKYGQ. KPIKGSPHPRGYYKCSTV . . . RGCPARKHVERAVDDPSMLIVTYEGEHRH DDYSWRKYGQ. KPIKGSPHPRGYYKCSSM. . . RGCPARKHVERCLEDPSMLIVTYEGEHNH DEFSWRKYGQ. KPIKGSPHPRGYYKCSSM. . . . RGCPARKIVERCLEDPSMLIVTYEGEHNH DLWSWRKYGQ. KPIKGSPYPRGYYRCSTS. . . . KGCSAKKQVERCRTDSSFLIITYTSSHNH DGYOWRKYGQ. KVTKDNPSPRAYERCSMAP . . . ACPVKKKVCRSLEDSSILIATYEGEHNH DGYKWRKYGQ.KSIKNSPNPR

T.HLLPTPNS.NTGNGEPSSMEYHQNFTF . . . . . . PLQHPQLQIPDQYDLLQDLLPÄEIDK DWWAWRKYGQ. KPIKGSPYPRNYYRCSSS. . . . KGCSARKQVERSNLDPNIFIVTYSGDHTH DKWAWRKYGQ. KPIKGSPYPRSYYRCSSS. . . KGCLARKQVERSREDPGVEIITYTAEHSH STASSNSTAA. NSHTPRSKRRGYYRCSSS . . . KGCLARKQVERNRSDPTIFIVTYTAEHNH NKFHHHLLGI . TMSHVSNPPNRKARVSVR. . . . . ARCQSSTVCRCIEDMSILITTYEGTHNH DNFSWRKYGQ . KEILGSR FPRAYYRCTHCKK . LY . NCPAKKQVCRLDDDPYMELVTYRGSHSC DGYNWRKYGQ. KQVKSPKGSRSYYKCTYS. . . . . NCSAKKIECSDHSGHVIEVNNKGMHSH CSAR FGALVAYAAVRGALGPSRVYRAKLH. . . . . GOGVPMEVECSR. STLVSRVPLVSLHGC EVKTRVEFYMDMGMNEKDFGTMVEDCPKVLGFFTLEDMSQKVCSHLYHIPSISENEGSMYSY

Fig. 2 Comparison of WRKY domain and zine figure signature of WRKY domain of papaya

$\mathrm{CX}_{4-5} \mathrm{CX}_{22-23} \mathrm{HX}_{1} \mathrm{H}$. The phylogenetic unrooted tree of the WRKY transcripts was shown in Fig. 1 with notes for induced expressions of 10 WRKYs under abiotic and biotic stresses.
The structural characteristics of the 52 WRKYs was demonstrated by comparing the detailed sequence of 60 amino acids at the N-terminer of the coding sequence containing at least one amino acid motif of WRKY (Fig. 2). 


\section{Expression of WRKY genes under abiotic stresses}

Expression of four WRKYs is significantly upregulated by low temperature

The expression levels of 13 WRKY TFs were analyzed under stress conditions. The results showed that the expression levels of $\mathrm{TF}_{807.3}$ and $\mathrm{TF}_{72.14}$ were induced by 14.3- and 16.2fold normalized against housekeeping gene actin whose relative mRNA expression was $2^{-\Delta \Delta \mathrm{Ct}}=1$ (significant at probability $<0.01$ ) after $12 \mathrm{~h}$ of low-temperature treatment $\left(4{ }^{\circ} \mathrm{C}\right) . \mathrm{TF}_{12.199}$ and $\mathrm{TF}_{18.51}$ were induced by 8.6 - and 5.5 -fold (significant at probability $<0.05$ ) after $12 \mathrm{~h}$ of $4{ }^{\circ} \mathrm{C}$ treatment. The expression levels of $\mathrm{TF}_{114.61}$ and $\mathrm{TF}_{21.156}$ were also notably up-regulated, but statistically insignificant (Fig. 3).

Six WRKYs are involved in the response to drought stress

Four WRKY genes were upregulated and two WRKYs were down-regulated under drought stress. The expression of $\mathrm{TF}_{807.3}$ and $\mathrm{TF}_{43.76}$ were increased by 14.12 - and 19.22 -fold at the significant level of probability $<0.01$. The expression of $\mathrm{TF}_{5.242}$ and $\mathrm{TF}_{21.156}$ were increased by 13.2- and
13.1 -fold at the significant level of probability $<0.05$. However, the expression of $\mathrm{TF}_{12.199}$ and $\mathrm{TF}_{12.62}$ were significantly ( $p<0.01$ ) decreased by 0.46 - and 0.39 -fold (Fig. 4).

Expression of five WRKYs is involved in response to wound

Changes in the transcript abundance of the 13 WRKY genes in response to wound treatment were examined. The transcript abundances of the WRKY genes of $\mathrm{TF}_{9.35}, \mathrm{TF}_{18.51}$ and $\mathrm{TF}_{72.14}$ were significantly $(p<0.01)$ increased $12 \mathrm{~h}$ after wounding. And the expression of $\mathrm{TF}_{807.3}$ were also significantly increased but at a lower probability level $(p<0.05)$. The expression abundance of $\mathrm{TF}_{12.199}$, however, was significantly ( $p<0.05)$ decreased (Fig. 5).

\section{Expression of WRKY genes under biotic stresses}

Expression of four WRKY genes was induced by PRSV pathogen

Three WRKY genes were upregulated and one $W R K Y$ were down-regulated when infected by PRSV pathogen. The
Fig. 3 Expression of WRKY genes in response to cold stress treatments in papaya. Changes in the WRKY transcript abundance as a result of $4{ }^{\circ} \mathrm{C}$ treatment for $12 \mathrm{~h}$

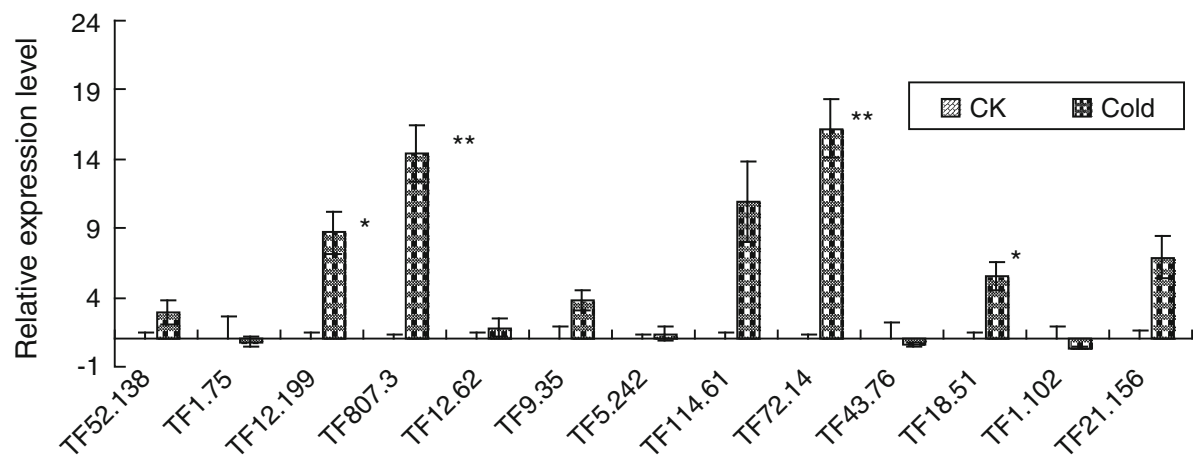

WRKY transcription factors in papaya

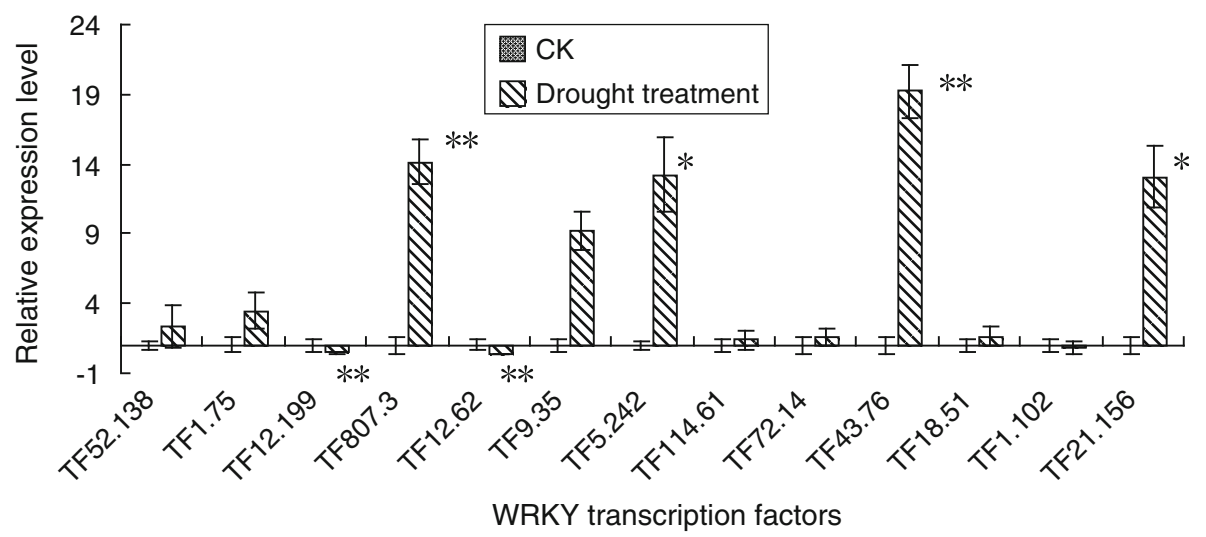


Fig. 5 Real-time qPCR of 13 genes to analyze their expression following wound stress treatments for $12 \mathrm{~h}$

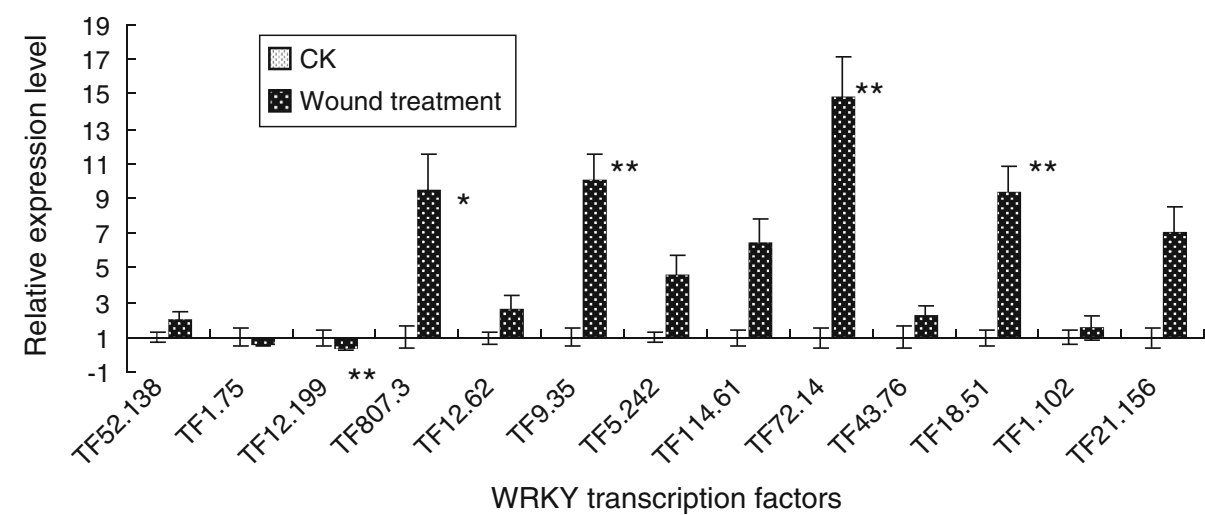

Fig. 6 The expression level of $W R K Y$ after PRSV infection at $24 \mathrm{~h}$

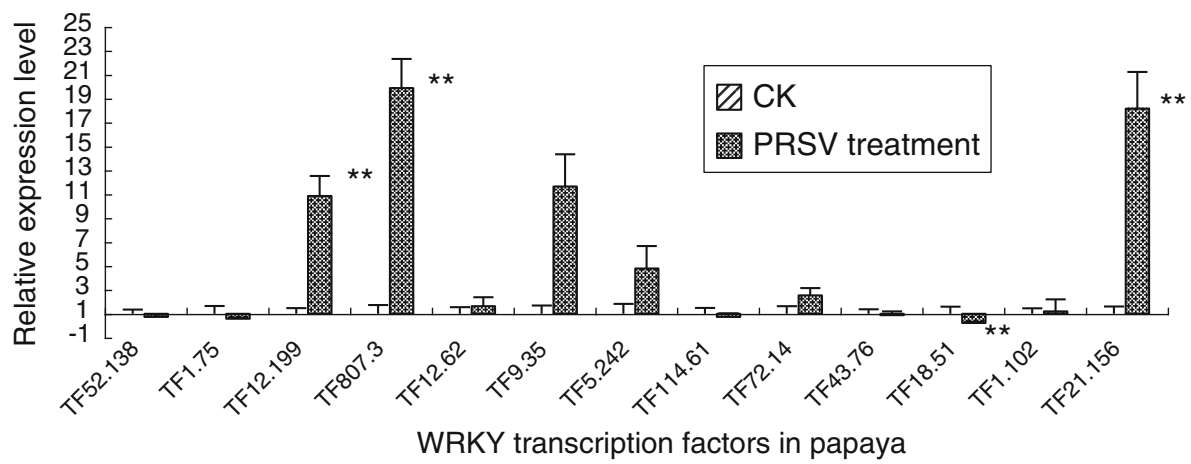

Fig. 7 Expression of WRKYs in response to SA treatment. Changes in WRKY transcript abundance in response to SA treatment after $12 \mathrm{~h}$

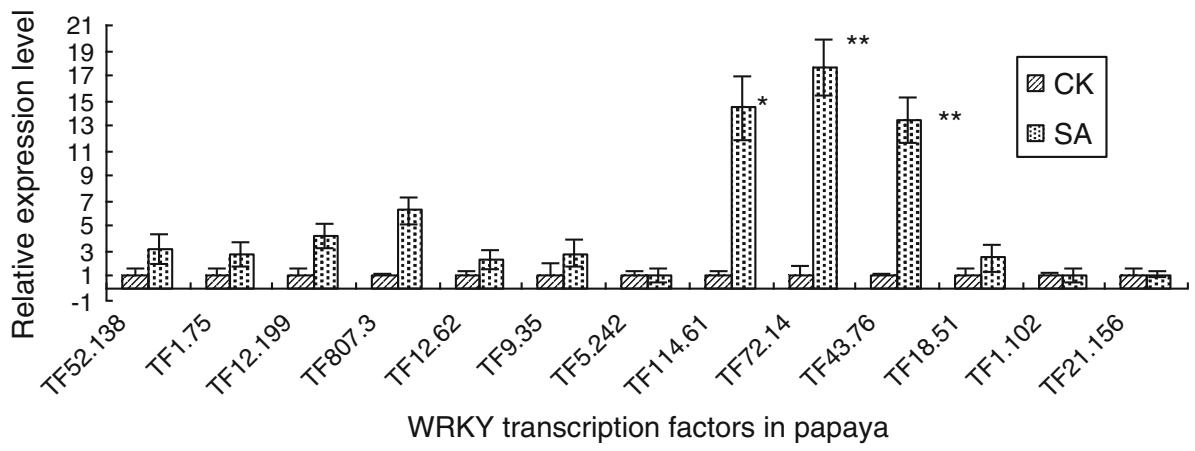

expression levels of $\mathrm{TF}_{12.199}, \mathrm{TF}_{807.3}$, and $\mathrm{TF}_{21.156}$ significantly increased ( $p<0.01$ ) by 10.8-, 19.8-, and 18.1-fold after $24 \mathrm{~h}$ of treatment. The expression level of $\mathrm{TF}_{18.51}$ was significantly decreased $(p<0.01)$ by 0.22 -fold (Fig. 6).

Expression of three $W R K Y$ genes is up-regulated by Salicylic acid

Salicylic acid (SA) plays a critical role in plant defense against pathogens. $\mathrm{TF}_{114.61}, \mathrm{TF}_{72.14}$, and $\mathrm{TF}_{43.76}$ were demonstrated to be induced by $\mathrm{SA}$ treatment. The transcription abundances of $\mathrm{TF}_{72.14}$ and $\mathrm{TF}_{43.76}$ were significantly increased $(p<0.01)$ by 17.6 - and 13.4 -fold at $12 \mathrm{~h}$ after the SA treatment, respectively. The transcription abundance of $\mathrm{TF}_{114.61}$ was increased by 14.4-fold which is significant at probability $<0.05$ level (Fig. 7).
Identification of $W R K Y s$ in response to abiotic and biotic stresses

A total of ten WRKYs were indentified in response to three abiotic and two biotic stresses (Table 1). Four WRKYs were up-regulated by low-temperature. Six $W R K Y s$ responded to drought stress, including four upregulated and two downregulated genes. Five WRKYs responded to wound, including four upregulated and one down-regulated genes. Four WRKYs were induced by PRSV pathogen, including three up-regulated and one down-regulated genes. And three WRKYs were up-regulated by SA.

A $W R K Y$ gene may respond to one stress or several different stresses. For example, the expression of $\mathrm{TF}_{807.3}$ and $\mathrm{TF}_{12.199}$ was found to be in response to four different stresses, respectively. $\mathrm{TF}_{807.3}$ was up-regulated by low-temperature, drought, wound 
Table 1 Expression of the WRKYs in response to abiotic and biotic stresses in papaya

$\uparrow$ and $\downarrow$ :The upregulated and down regulated expression levels of WRKY genes normalized against

housekeeping gene actin were significant at probability of 0.01 level

$\uparrow$ and $\downarrow$ : The upregulated and down regulated expression levels of $W R K Y$ genes normalized against housekeeping gene actin were significant at probability of 0.05 level

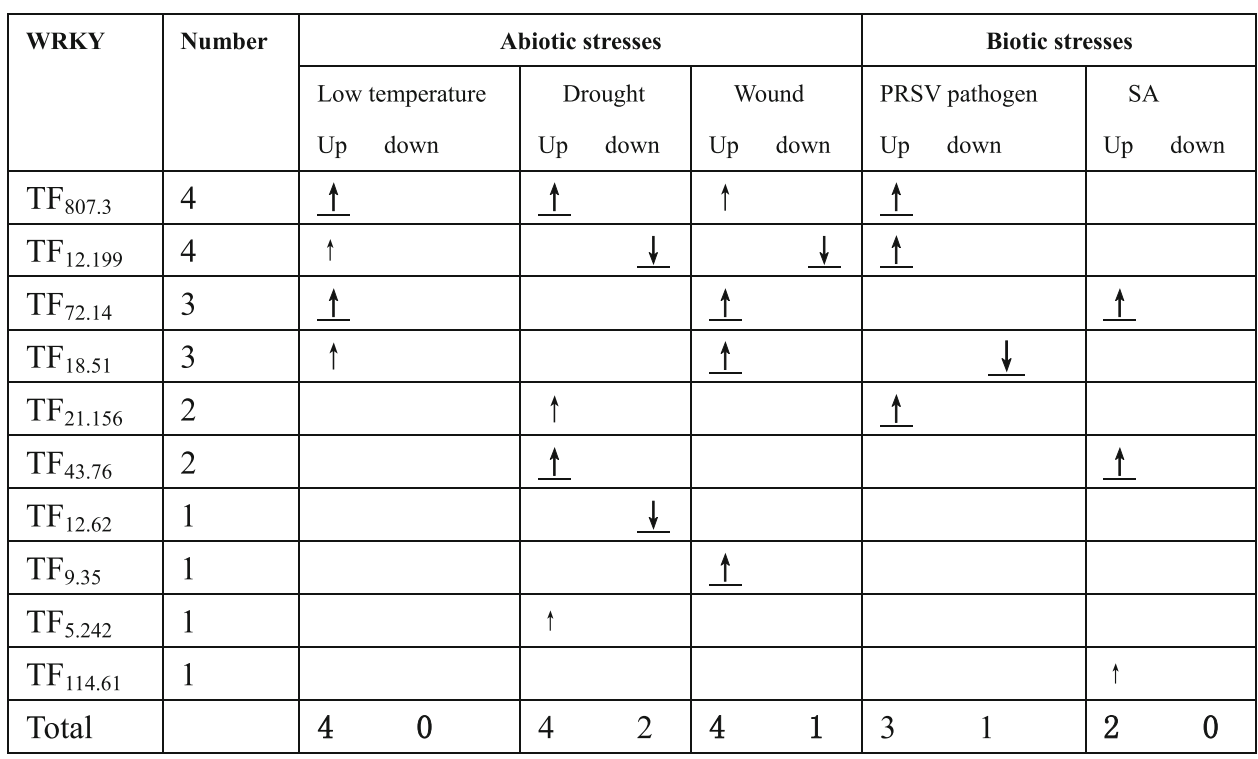

and PRSV pathogen. $\mathrm{TF}_{12.199}$ was up-regulated by low-temperature and PRSV pathogen but down-regulated by drought and wound. The expression of $\mathrm{TF}_{72.14}$ and $\mathrm{TF}_{18.51}$ responded to three different stresses, respectively. The expression of $\mathrm{TF}_{21.156}$ and $\mathrm{TF}_{43.76}$ was up-regulated by two different stresses, respectively. While the expression of $\mathrm{TF}_{12.62}, \mathrm{TF}_{9.35}, \mathrm{TF}_{14.61}$ and $\mathrm{TF}_{14.61}$ were in response to single stress, respectively.

Homological comparison between WRKYs of papaya and that of other plants

Homological analysis on the detailed sequence of 60 amino acids was made between the ten WRKYs and nine AtWRKY in Arabidopsis, seven OsWRKY in rice, seven GmWRKY in soybean, one NtWRKY in tobacco, and one VvWRKY in grape (Supplement Fig. 1). The homology of the WRKY TFs in papaya and the WRKYs with known functions in other plants were analyzed by DNAman. Results indicate that $\mathrm{TF}_{12.199}$ shares $100 \%$ homology with GmWRKY3 and GmWRKY6, $\mathrm{TF}_{72.14}$ shares $88.5 \%$ homology with AtWRKY33, $\mathrm{TF}_{9.35}$ shares $80.3 \%$ homology with OsWRKY3, $\mathrm{TF}_{43.76}$ and $\mathrm{TF}_{807.3}$ share 78.9 and $75.5 \%$ homology with OsWRKY23 respectively, $\mathrm{TF}_{12.62}$ shares $75.4 \%$ homology with OsWRKY53. The high homology suggests that the WRKYs in papaya may have similar functions with their homologous genes in other species.

\section{Discussion}

Characteristics of the WRKY TFs in C. papaya

WRKY TFs contain one or two conserved WRKY domains, which can recognize and bind to the TTGAC(C/T) W-box elements found in the promoters of a large number of plant defense-related genes [9, 20, 51]. The detailed nucleotide sequence information of $52 W R K Y$ genes was mined using bio-information methods in this study. This information could be used to facilitate the further research of WRKY genes in $C$. papaya.

WRKY TFs can be classified based on both the number of WRKY domains and the features of their zinc-finger motif. WRKY TFs are usually classified into three or four groups. 72 WRKYs have been reported in Arabidopsis, 15 WRKYs belong to group I, 43 belong to group II and 14 belong to group III. 96 WRKYs have been found in rice, 13 WRKYs belong to group I, 45 belong to group II, 32 belong to group III, and 6 belong to group IV [50]. The group II including a conserved WRKYGQK heptapeptide followed by a zine finger $\mathrm{CX}_{4-5} \mathrm{CX}_{22-23} \mathrm{HHX}_{1} \mathrm{H}$ is the largest group in most plants [10, 50]. In this research, 52 WRKYs in papaya have been classified into 4 groups, 6 WRKYs belong to group I, 32 WRKYs belong to group II, 7 belong to group III, and 7 belong to group IV. Group II is also the largest in papaya.

Homological analysis between the 10 WRKYs induced by abiotic and biotic stresses and WRKYs with known functions in other plants revealed striking similarities in the conserved sequence of 60 amino acids. $\mathrm{TF}_{12.199}$ in papaya has exactly the same sequence of 60 amino acids as that of GmWRKY3 and GmWRKY6 in soybean [58].

In present experiment, 13 WRKY genes with high mRNA abundance were selected as the target for qPCR, 4 WRKYs belong to group I and 9 belong to group II. And 10 out of the 13 WRKYs including 3 WRKYs in group I and 7 WRKYs in group II were found to respond to abiotic and/ or biotic stresses. This suggests that the WRKYs of groups I and II in papaya may be more sensitive to stresses. 
Mining the WRKYs relative to the resistance against PRSV pathogen in papaya

A large number of $W R K Y$ genes are induced by pathogens or plant defense signal molecules. In Arabidopsis, 49 of 72 WRKY genes tested were differentially regulated in plants after infection with an avirulent strain of $P$. syringae or treatment with SA [7]. A few WRKYs were testified to have certain functions in Arabidopsis, and several WRKYs have been proven to possess functions related to disease resistance. For example, NtWRKY3 message was induced rapidly upon infection with TMV in tobacco [2, 51]. AtWRKY70 enhanced the resistance to both Pseudomonas syringae and Erysiphe chichoracearum [25]. And AtWRKY3, AtWRKY4 and AtWRKY41 had the function of enhancing the resistance to $P$. syringae $[14,23]$. In this study, the expression of $\mathrm{TF}_{12.199}, \mathrm{TF}_{807.3}$ and $\mathrm{TF}_{21.156}$ were up-regulated and $\mathrm{TF}_{18.51}$ was down-regulated trend after PRSV infection. The expression of both $\mathrm{TF}_{43.76}$ and $\mathrm{TF}_{72.14}$ were up-regulated after SA treatment. 7 out of 13 WRKYs were differentially regulated by PRSV and/or SA in papaya. This suggests the possibility of mining the WRKYs relative to the resistance against PRSV pathogen in papaya.

Homological and functional comparison

between WRKYs in $C$. papaya and other plants

Proteins with similar domains may have the same or similar biologic functions [28]. For example, NtWRKY3 in tobacco share high homology at the amino acid level with Arabidopsis AtWRKY4 and WRKY70, respectively. NtWRKY3 was induced rapidly upon infection with TMV [2]. AtWRKY4 could enhance the resistance to Pseudomonas syringae [23]. AtWRKY70 was induced by SA, JA and could enhance the resistance to P. syringae and Erysiphe chichoracearum [25]. The three homological genes all have functions in responding to disease resistance.

AtWRKY33 is a multifunctional TF that is involved in both abiotic and biotic stress responses. AtWRKY33 regulated the antagonistic relationship between defense pathways mediating responses to $P$. syringae and necrotrophic pathogens [56]. And AtWRKY33 was up-regulated 14 times after $\mathrm{NaCl}$ stress treatment [18]. The sequence of $\mathrm{TF}_{72.14}$ shared $88.5 \%$ homology with that of AtWRKY33. $\mathrm{TF}_{72.14}$ was demonstrated to be induced by low temperature, wound and SA treatment in papaya.

OsWRKY 3 in rice was induced by Botrytis \& $P$. syringae infection and SA, JA, ACC. It expressed the resistance to Pseudomonas syringae [23]. $\mathrm{TF}_{9.35}$ shared $80.3 \%$ homology with $O s W R K Y 3$. The transcript abundance of $\mathrm{TF}_{9.35}$ was significantly increased after wounding.

A number of TFs being activated by abiotic stress could also be induced by pathogen infection [4]. The sequence of
$\mathrm{TF}_{12.199}$ shared $100 \%$ homology with that of GmWRKY6 which was related to drought resistance in soybean [58]. The expression level of $\mathrm{TF}_{12.199}$ was increased by cold and PRSV, but was decreased by wound and drought treatments. $\mathrm{TF}_{12.199}$ could be a multifunctional TF involved in both abiotic and biotic stress responses in papaya.

The potential application of the WRKYs in C. papaya

The WRKY genes in papaya has been studies by analyzing their nucleotide sequence information, classification according to their characteristics of WRKY type domain, and detecting the expression of WRKY TFs under three biotic and two abiotic stresses. Ten WRKYs have been detected to be in response to the stresses. The regulated expression levels of eight out of ten WRKYS are significant at probability of 0.01 levels. These WRKY TFs could be related to corresponding stress tolerance. Two WRKYs, $\mathrm{TF}_{807.3}$ and $\mathrm{TF}_{12.199}$, each regulated by four different stresses, are of especially interesting for further functional verification. This study may provide useful information for the genetic improvement and candidate genes for the development of transgenic stress tolerant papaya varieties.

Acknowledgments The Project was supported by the National Science Foundation items in China of No. 30771477 and No. 30571277. We thank Prof. De Ming JIN of Huazhong Agricultural University for his helpful discussions and critical reading the manuscript.

Open Access This article is distributed under the terms of the Creative Commons Attribution License which permits any use, distribution, and reproduction in any medium, provided the original author(s) and the source are credited.

\section{References}

1. Agarwal P, Reddy MP, Chikara J (2011) WRKY: its structure, evolutionary relationship, DNA-binding selectivity, role in stress tolerance and development of plants. Mol Biol Rep 38:38833896

2. Chen C, Chen Z (2000) Isolation and characterization of two pathogen- and salicylic acid-induced genes encoding WRKY DNA-binding proteins from tobacco. Plant Mol Biol 42:387-396

3. Chen H, Lai ZB, Shi JW, Xiao Y, Chen ZX, Xu XP (2010) Roles of arabidopsis WRKY18, WRKY40 and WRKY60 transcription factors in plant responses to abscisic acid and abiotic stress. BMC Plant Biol 10:281. doi:10.1186/1471-2229-10-281

4. Chen WQ, Provart NJ, Glazebrook J, Katagiri F, Chang HS, Eulgem T, Mauch F, Luan S, Zou G, Whitham SA et al (2002) Expression profile matrix of arabidopsis transcription factor genes suggests their putative functions in response to environmental stresses. Plant Cell 14:559-574

5. Chujo T, Sugioka N, Masuda Y, Shibuya N, Takemurat OkadaK, Nojiri H, Yamane H (2009) Promoter analysis of the elicitorinduced WRKY gene OsWRKY53, which is involved in defense responses in rice. Biosci Biotechnol Biochem 73(8):1901-1904 
6. Dellagi A, Birch PRJ, Heilbronn J, Avrova AO, Montesano M, Palva ET, Lyon GD (2000) A potato gene, erg-1, is rapidly induced by Erwinia carotovora ssp. atroseptica, Phytophthora infestans, ethylene and salicylic acid. J Plant Physiol 157:201-205

7. Dong J, Chen C, Chen Z (2003) Expression profiles of the Arabidopsis WRKY gene superfamily during plant defense response. Plant Mol Biol 51:21-37

8. Encinas-Villarejo S, Maldonado AM, Amil-Ruiz F, de los Santos B, Romero F, Pliego-Alfaro F, Muñoz-Blanco J, Caballero JL (2009) Evidence for a positive regulatory role of strawberry (Fragaria ananassa) Fa WRKY1 and arabidopsis at WRKY75 proteins in resistance. J Exp Bot 60:3043-3065

9. Eulgem T, Somssich IE (2007) Networks of WRKY transcription factors in defense signaling. Curr Opin Plant Biol 10:366-371

10. Eulgem T, Rushton PJ, Robatzek S, Somssich IE (2000) The WRKY superfamily of plant transcription factors. Trends Plant Sci 5:199-206

11. Fan H, Wang F, Gao H, Wang L, Xu J, Zhao Z (2011) Pathogen induced MdWRKY1 in 'Qinguan' apple enhances disease resistance. J Plant Biol 54(3):150-158

12. Golldack D, King IL, Yang O (2011) Plant tolerance to drought and salinity: stress regulating transcription factors and their functional significance in the cellular transcriptional network. Plant Cell Rep 30:1383-1391

13. Guilllaumie S, Mzid R, Mechin V, Leon C, Hichri S, Gestraclvine A, Trossat-Magnin C, Delrot S, Lauvergeat V (2010) The grapevine transcription factor WRKY2 in flounces the lignin pathway and xylem development into tobacco. Plant Mol Biol 72:215-234

14. Higashi K, Ishiga Y, Inagaki Y, Toyoda K, Shiraishi T, Ichinose Y (2008) Modulation of defense signal transduction by flagellin induced WRKY41 transcription factor in Arabidopsis thaliana. Mol Genet Genomics 279(3):303-312

15. Hwang SH, Yie SW, Hwanga DJ (2011) Heterologous expression of OsWRKY6 gene in Arabidopsis activates the expression of defense related genes and enhances resistance to pathogens. Plant Sci 181:316-323

16. Ishiguro KS, Kobayashi S, Omore A, Takamatsu S, Yonekura K, Anzai K, Imahori K, Uchida $T$ (1994) Identification of the $23 \mathrm{kDa}$ subunit of tau protein kinase II as a putative activator of Cdk5 in bovine brain. FEBS Lett 342:203-208

17. Lim JH, Park CJ, Huh SU, Choi LM, Lee GJ, Kim YJ (2011) Capsicum annuum WRKYb transcription factor that binds to the CaPR-10 promoter functions as a positive regulator in innate immunity upon TMV infection. Biochem Biophys Res Commun 411:613-619

18. Jiang Y, Deyholos MK (2009) Functional characterization of Arabidopsis NaCl-inducible WRKY25 and WRKY33 transcription factors in abiotic stresses. Plant Mol Biol 69(1-2):91-105

19. Jiang W, Yu D (2009) Arabidopsis WRKY2 transcription factor mediates seed germination and postgermination arrest of development by abscisic acid. BMC Plant Biol 9:96. doi:10.1186/ 1471-2229-9-96

20. Jing SJ, Zhou X, Song Y, Yu DQ (2009) Heterogonous expression of OsWRKY23 gene enhances pathogen defense and darkinduced leaf senescence in Arabidopsis. Plant Growth Regul 58(2):181-190

21. Kakar K, Warendrey M, Czechowwki T, Gaertner T, Scheible W, Stitt M, Torres-Jerez I, Xiao Y, Redman JC, Wu H et al (2008) A community resource for high-throughput quantitative RT-PCR analysis of transcription factor gene expression in Medicago truncatula. Plant Methods 4:18. doi:10.1186/1746-4811-4-18

22. Kim KC, Lai Z, Fan B, Chen Z (2008) Arabidopsis WRKY38 and WRKY62 transcription factors interact with histone deacetylase 19 in basal defense. Plant Cell 20:2357-2371
23. Lai Z, Vinod KM, Zheng Z, Fan B, Chen Z (2008) Roles of Arabidopsis WRKY3 and WRKY4 transcription factors in plant responses to pathogens. BMC Plant Biol 8:68. doi:10.1186/14712229-8-68

24. Leve 'e V, Major I, Levasseur C, Tremblay L, Mackay J, Se 'guin A (2009) Expression profiling and functional analysis of populus WRKY23 reveals a regulatory role in defense. New Phytol 184(1):48-70

25. Li J, Brader G, Palva ET (2004) The WRKY70 transcription factor: a node of convergence for jasmonate-mediated and salicylatemediated signals in plant defense. Plant Cell 16:319-331

26. Li R, Lou YG (2011) Research advances on stress responsive WRKY transcription factors in plants. Acta Ecologica Sinica 31(11):3223-3231

27. Ling J, Jiang WJ, Zhang Y, Yu HJ, Mao ZC, Gu XF, Huang SW, Xie BY (2011) Genome-wide analysis of WRKY gene family in Cucumis sativus. BMC Genomics 12: 471 http://www.bio medcentral.com/1471-2164/12/471

28. Liu XQ, Bai XQ, Qian Q, Wang XJ, Chen MS, Chu CC (2005) OsWRKY03, a rice transcriptional activator that functions in defense signaling pathway upstream of OsNPR1. Cell Res 15(8):593-603

29. Liu Y, Schiff M, Dinesh-Kumar SP (2004) Involvement of MEK1 MAPKK, NTF6 MAPK, WRKY/MYB transcription factors, COI1 and CTR1 in N-mediated resistance to tobacco mosaic virus. Plant J 38:800-809

30. Livak KJ, Schmittgen TD (2001) Analysis of relative gene expression. Data using real time quantitative PCR and the $2^{-\Delta \Delta \mathrm{Ct}}$ method. Methods 25:402-408

31. Marchive C, Mzid R, Deluc L, Barrieu F, Pirrello J, Gauthier A, Corio-Costet MF, Regad F, Cailleteau B, Hamdi S et al (2007) Isolation and characterization of a Vitis vinifera transcription factor, VvWRKY1, and its effect on responses to fungal pathogens in transgenic tobacco plants. J Exp Bot 58:1999-2010

32. Mare C, Mazzucotelli E, Crosatti C, Francia E, Stanca AM, Cattivelli L (2004) HvWRKY38: a new transcription factor involved in cold- and drought-response in barley. Plant Mol Biol 55:399-416

33. Ming R, Hou S, Feng Y et al (2008) The draft genome of the transgenic tropical fruit tree papaya (Carica papaya Linnaeus). Nature 452:991-996

34. Mukhtar MS, Deslandes L, Auriac MC (2008) The Arabidopsis transcription factor WRKY27 influences wilt disease symptom development caused by Ralstonia solanacearum. Plant $\mathrm{J}$ 56(6):935-947

35. Mzid R, Marchive C, Blancard D, Deluc L, Barrieu F, CorioCostet MF, Drira N, Hamdi S, Lauvergeat V (2007) Overexpression of VvWRKY2 in tobacco enhances broad resistance to necrotrophic fungal pathogens. Physiol Plant 131(3):434-447

36. Oh SK, Bek KH, Park JM, Yi SY, Yu SH, Kamoun S, Choi D (2008) Capsicum annuum WRKY protein CaWRKY1 is a negative regulator of pathogen defense. New Phytol 177(4):977-989

37. Pape S, Thurow C, Gatz C (2010) The arabidopsis PR-1 promoter contains multiple integration sites for the coactivator NPR1 and the repressor SNI1. Plant Physiol 154:1805-1818

38. Park CJ, Shin YC, Lee BJ, Kim KJ, Kim JK, Paek KH (2006) A hot pepper gene encoding WRKY transcription factor is induced during hypersensitive response to Tobacco mosaic virus and Xanthomonas campestris. Planta 223:168-179

39. Peng XX, Hu YJ, Tang XK, Zhou PL, Deng XB, Wang HH, Guo ZJ (2012) Constitutive expression of rice WRKY30 gene increases the endogenous jasmonic acid accumulation, PR gene expression and resistance to fungal pathogens in rice. Planta 236:1485-1498

40. Ramamoorthy R, Jiang SY, Kumar N, Venkatesh PN, Ramachandran S (2008) A comprehensive transcriptional profiling of 
the WRKY gene family in rice under various abiotic and phytohormone treatments. Plant Cell Physiol 49(6):865-879

41. Ross CA, Liu Y, Shen QJ (2007) The WRKY gene family in rice (Oryza sativa). J Integr Plant Biol 49:827-842

42. Rushton PJ, Somssich EI, Ringler P, Shen QJ (2011) WRKY transcription factors. Trends Plant Sci 15(5):247-258

43. Ryu HS, Han M, Lee SK, Cho JI, Ryoo N, Heu S, Lee YH, Bhoo S, Wang GL, Hahn TR et al (2006) A comprehensive expression analysis of the $W R K Y$ gene superfamily in rice plants during defense response. Plant Cell Rep 25:836-847

44. Sun CX, Palmqvist S, Olsson H, Boren M, Ahlandsberg S, Jansson C (2003) A novel WRKY transcription factor, SUSIBA, participates in sugar signaling in barley by binding to the sugar-responsive elements of the iso1 promoter. Plant Cell 15(9):2076-2092

45. Van Verk MC, Pappaioannou D, Neeleman L, Bol JF, Linthorst HJM (2008) A novel WRKY transcription factor is required for induction of PR-1a gene expression by salicylic acid and bacterial elicitors. Plant Physiol 146(4):1983-1995

46. Wang H, Hao J, Chen X, Hao Z, Wang X, Lou Y, Peng Y, Guo Z (2007) Overexpression of rice WRKY89 enhances ultraviolet B tolerance and disease resistance in rice plants. Plant Mol Biol 65:799-815

47. Xie Z, Zhang ZL, Zou XL, Yang GX, Komatsu S, Shen QJ (2006) Interactions of two abscisic-acid induced WRKY genes in repressing gibberellin signaling in aleurone cells. Plant $\mathbf{J}$ 46:231-242

48. Xie Z, Zhang ZL, Hanzlik S, Cook E, Shen QJ (2007) Salicylic acid inhibits gibberellin-induced alpha-amylase expression and seed germination via a pathway involving an abscisic-acid inducible WRKY gene. Plant Mol Biol 64:293-303

49. Xu X, Chen C, Fan B, Chen Z (2006) Physical and functional interactions between pathogen-induced Arabidopsis WRKY18, WRKY40, and WRKY60 transcription factors. Plant Cell 18:1310-1326

50. Yang B, Jiang YQ, Rahman MH, Deyholos MK, Kav NNV (2009) Identification and expression analysis of WRKY transcription factor genes in canola (Brassica napus L.) in response to fungal pathogens and hormone treatments. BMC Plant Biol 9:68. doi:10.1186/1471-2229-9-68
51. Yang P, Chen C, Wang Z, Fan B, Chen Z (1999) A pathogen- and salicylic acid-induced WRKY DNA-binding activity recognizes the elicitor response element of the tobacco class I chitinase gene promoter. Plant J 18:141-149

52. Yao DX, Zhang XY, Zhao XH, Liu CL, Wang CH, Zhang ZH, Zhang CJ, Wei Q, Wang QH, Yan H, Li FG, Su Z (2011) Transcriptome analysis reveals salt-stress-regulated biological processes and key pathways in roots of cotton (Gossypium hirsutum L.). Genomics 98:47-55

53. Yoda H, Ogawa M, Yamaguchi Y, Koizumi N, Kusano T, Sano H (2002) Identification of early-responsive genes associated with the hypersensitive response to tobacco mosaic virus and characterization of a WRKY-type transcription factor in tobacco plants. Mol Genet Genomics 267(2):154-161

54. Zeng T, Kou YJ, Liu HB, Li XH, Wang SP (2011) OsWRKY45 alleles play different roles in abscisic acid signalling and salt stress tolerance but similar roles in drought and cold tolerance in rice. J Exp Bot 62(14):4863-4874

55. Zhang J, Peng Y, Guo Z (2008) Constitutive expression of pathogen-inducible OsWRKY31 enhances disease resistance and affects root growth and auxin response in transgenic rice. Cell Res 18:508-521

56. Zhen ZY, Abu Qamar S, Chen ZX, Mengiste T (2006) Arabidopsis WRKY33 transcription factor is required for resistance to necrotrophic fungal pathogens. Plant J 48(4):592-605

57. Zheng JY, Zou XX, Mao ZC, Xie BY (2011) A novel pepper (Capsicum annuum L.) WRKY gene, CaWRKY30 is involved in pathogen stress responses. J Plant Biol 54:329-337

58. Zhou QY, Tian AG, Zou HF, Xie ZM, Lei G, Huang J, Wang CM, Wang HW, Zhang JS, Chen SY (2008) Soybean WRKYtype transcription factor genes, GmWRKY13, GmWRKY21, and GmWRKY54, confer differential tolerance to abiotic stresses in transgenic Arabidopsis plants. Plant Biotechnol J 6:486-503

59. Zou X, Seemann JR, Neuman D, Shen QJ (2004) A WRKY gene from creosote bush encodes an activator of the abscisic acid signaling pathway. J Biol Chem 279:55770-55779

60. Zou XL, Shen QJ, Neuman D (2007) An ABA inducible WRKY gene integrates responses of creosote bush Larrea tridentata to elevated $\mathrm{CO}_{2}$ and abiotic stresses. Plant Sci 172:997-1004 